\title{
Socioeconomic and Demographic Characteristics of Both Inpatients and Outpatients with Positive Testing for SARS-CoV-2
}

$\mathrm{J}$ Gen Intern Med 36(8):2522-4

DOI: $10.1007 / \mathrm{s} 11606-021-06919-\mathrm{x}$

(C) Society of General Internal Medicine 2021

$\mathrm{T}$ here have been marked disparities in both infections and deaths from the COVID-19 pandemic in the USA, highlighting societal and structural factors. Some limitations of previous work include restriction to inpatients ${ }^{1,2}$ and inability to distinguish between ecological/group and individual associations. ${ }^{3,4}$ In that setting, we used a granular dataset of SARS-CoV-2 testing including inpatients and outpatients to assess the association between positive tests and socioeconomic and demographic characteristics of individuals.

\section{METHODS}

We queried SARS-CoV-2 tests from March 3 to December 14, 2020, within a large, integrated network that includes 14 hospitals, community physicians, health centers, and urgent care centers. Tests were included for patients with medical record numbers attributable to the Massachusetts General Hospital (MGH), which are patients who have received care at MGH including outpatient clinics and community health centers at any point in the past. We identified positive and negative tests, then queried the integrated electronic health record to determine patient-level gender, race/ethnicity, insurance status, and zip code. We then extracted zip code level median household income, pre-pandemic unemployment rate, poverty rate, and proportion of workers in service occupations as defined in the 2015-2019 American Community Survey (ACS). Patients with missing zip code data $(0.05 \%)$ and patients who live outside Massachusetts were excluded. Test positivity was defined as a binary, patient-level outcome. When patients had multiple tests, we used the last test. Due to high collinearity (data not shown), we decided to present bivariate chi-squared tests between the primary outcome of interest and each socioeconomic and demographic variable separately. To assess for selection bias, we also queried the

Received February 11, 2021

Accepted May 5, 2021

Published online June 8, 2021 proportion of patients receiving any type of care at MGH who are uninsured. This study was performed in SAS version 9.4 and was approved by the Mass General Brigham Institutional Review Board.

\section{RESULTS}

Of 394,536 tested patients, 29,977 (7.6\%) had positive tests (Table 1). Males had more positive tests than females $(8.2 \%$ vs. $7.2 \%, p<0.0001)$. Hispanic and Black patients had more positive tests than White patients $(17.2 \%$ vs. $11.9 \%$ vs. $5.6 \%$, respectively, $p<0.0001$ for both). Medicaid patients had more positive tests than commercial insurance patients (14.2\% vs. $6.8 \%, p<0.0001)$.

In terms of differences among zip codes, zip codes with median household income less than or equal to $\$ 70,000$ per year had more positive tests than zip codes with an estimated household income greater than $\$ 100,000$ per year (13.3\% vs. $4.7 \%, p<0.001)$; zip codes with unemployment of greater than $5 \%$ had more positive tests than patients in zip codes with unemployment of $3.5 \%$ or less $(10.7 \%$ vs. $5.8 \%, p<0.001)$; and zip codes with greater than $20 \%$ of people working in the service sector had more positive tests than those in zip codes with $10 \%$ or fewer of people working in the service sector $(13.4 \%$ vs. $4.2 \%, p<0.001)$.

Including all predictor variables in multivariate regression did not change the directionality of our findings.

\section{DISCUSSION}

Positive SARS-CoV-2 tests are highly correlated with race and poverty. Black and lower income patients tested positive more than double the proportion of White and higher-income patients. Patients in zip codes with higher proportions of service sector workers had more than triple the likelihood of positive tests. A notable strength of our analysis is that we used patient-level data for gender, race, and insurance, although we imputed measures of poverty and employment from zip code medians and proportions. A limitation of our analysis is the external validity of extrapolating MGH patients to broader populations, particularly if there are differences in socioeconomic and demographic characteristics. We are reassured, however, for example, that the Black population 
Table 1 Association of Positive Tests with Individual and Zip Code Characteristics

\begin{tabular}{|c|c|c|c|c|}
\hline Covariate & Total no. of patients, $N(\%)$ & Tested negative, $N(\%)$ & Tested positive, $N(\%)$ & $p$ value \\
\hline Individual characteristics & & & & $<0.0001$ \\
\hline \multicolumn{5}{|l|}{ Gender } \\
\hline Male & $165,539(42.0)$ & $151978(91.8)$ & $13561(8.2)$ & \\
\hline Female & $228,997(58.0)$ & $212581(92.8)$ & $16416(7.2)$ & \\
\hline \multicolumn{4}{|l|}{ Race/ethnicity } & $<0.0001$ \\
\hline Asian & $14,859(3.8)$ & $13959(93.9)$ & $900(6.1)$ & \\
\hline Black & $27,467(7.0)$ & $24211(88.1)$ & $3256(11.9)$ & \\
\hline Hispanic & $5679(1.4)$ & $4703(82.8)$ & $976(17.2)$ & \\
\hline White & $287,441(72.9)$ & $271327(94.4)$ & $16,114(5.6)$ & \\
\hline Others & $30,342(7.7)$ & $24593(81.1)$ & $5749(18.9)$ & \\
\hline Declined or missing & $28,748(7.3)$ & $25766(89.6)$ & $2982(10.4)$ & \\
\hline \multicolumn{4}{|l|}{ Payor } & $<0.0001$ \\
\hline Commercial & $261,586(66.3)$ & $243798(93.2)$ & $17,788(6.8)$ & \\
\hline Medicaid & $54,989(13.9)$ & $47194(85.8)$ & $7795(14.2)$ & \\
\hline Medicare & $70,854(18.0)$ & $66964(94.5)$ & $3890(5.5)$ & \\
\hline Uninsured & $1902(0.5)$ & $1607(84.5)$ & $295(15.5)$ & \\
\hline Missing & $5205(1.3)$ & $4996(96.0)$ & $209(4.0)$ & \\
\hline \multicolumn{5}{|l|}{ Zip code characteristics* } \\
\hline \multicolumn{5}{|l|}{ Median HH income } \\
\hline $70 \mathrm{~K} \mid$ less & $10,5849(26.8)$ & $91788(86.7)$ & $14,061(13.3)$ & \\
\hline $71 \mathrm{~K}-100 \mathrm{~K}$ & $124,648(31.6)$ & $116465(93.4)$ & $8183(6.6)$ & \\
\hline$>100 \mathrm{~K}$ & $164,039(41.6)$ & $156306(95.3)$ & $7733(4.7)$ & \\
\hline \multicolumn{4}{|l|}{ Unemployment rate } & $<0.0001$ \\
\hline $3.5 \%$ or less & $140,014(35.5)$ & $131845(94.2)$ & $8169(5.8)$ & \\
\hline $3.6-5.0 \%$ & $147,514(37.4)$ & $137144(93.0)$ & $10,370(7.0)$ & \\
\hline$>5 \%$ & $107,008(27.1)$ & $95570(89.3)$ & $11,438(10.7)$ & \\
\hline \multicolumn{4}{|l|}{ Poverty rate } & $<0.0001$ \\
\hline $5 \%$ or less & $122,118(31.0)$ & $116713(95.6)$ & $5405(4.4)$ & \\
\hline $5.01-15.0 \%$ & $195,369(49.5)$ & $181427(92.9)$ & $13,942(7.1)$ & \\
\hline$>15 \%$ & $77,049(19.5)$ & $66419(86.2)$ & $10,630(13.8)$ & \\
\hline \multicolumn{4}{|l|}{$\%$ Working in service occupations } & $<0.0001$ \\
\hline$\leq 10 \%$ & $76,905(19.5)$ & $73701(95.8)$ & $3204(4.2)$ & \\
\hline $10.01-20 \%$ & $203,635(51.6)$ & $192128(94.3)$ & $11,507(5.7)$ & \\
\hline$>20 \%$ & $113,996(28.9)$ & $98730(86.6)$ & $15,266(13.4)$ & \\
\hline
\end{tabular}

*Data Source: American Community Survey 2015-2019. All neighborhood characteristics are defined at the zip code level

in this dataset $(7.0 \%)$ is similar to the proportion in New England $(8.1 \%)$ although the proportion of Hispanic patients is lower than in New England (11.6\%). ${ }^{5}$ This difference may in part reflect less SARS-CoV-2 testing in less affluent communities in Massachusetts. ${ }^{6}$ We found that the proportion of all MGH patients who are uninsured is $0.4 \%$, similar to this dataset of tested patients $(0.5 \%)$ but less than the uninsured in Massachusetts $(2.9 \%)$. As such, our results may not be generalizable to systems that care for more uninsured patients. ${ }^{7}$ Our results suggest a large role of structural and societal inequities in the consequences of the COVID-19 pandemic in the USA.

Jason H. Wasfy, M.D., M.Phil. ${ }^{1,2}$

Michael K. Hidrue, Ph.D. ${ }^{2}$

Helaine Rockett, M.P.H. ${ }^{3}$

Elizabeth T. Cafiero-Fonseca, S.M. ${ }^{3}$

Timothy G. Ferris, M.D., M.P.H. ${ }^{2,4,6}$

Marcela G. del Carmen, M.D., M.P.H. ${ }^{2,5}$

${ }^{1}$ Cardiology Division, Department of Medicine, Massachusetts General Hospital, Harvard Medical School,

Boston, MA, USA

${ }^{2}$ Massachusetts General Physicians Organization,

Boston, MA, USA
${ }^{3}$ Performance Analysis and Improvement, Massachusetts General Hospital,

Boston, MA, USA

${ }^{4}$ Department of Medicine, Massachusetts General Hospital, Harvard Medical School,

Boston, MA, USA

${ }^{5}$ Division of Gynecologic Oncology, Department of Obstetrics and Gynecology, Massachusetts General Hospital, Harvard Medical School,

Boston, MA, USA

${ }^{6}$ National Health Service, London, UK

Corresponding Author: Jason H. Wasfy, M.D., M.Phil.; Cardiology Division, Department of Medicine, Massachusetts General Hospital, Harvard Medical School, Boston, MA, USA (e-mail: jwasfy@mgh.harvard.edu).

Funding This work has been supported by a grant from the American Heart Association (18 CDA 34110215) awarded to Dr. Wasfy as well as funding from the Massachusetts General Physicians Organization.

\section{Declarations:}

Conflict of Interest: The authors declare that they do not have a conflict of interest. 


\section{REFERENCES}

1. Karaca-Mandic P, Georgiou A, Sen S. Assessment of COVID-19 Hospitalizations by Race/Ethnicity in 12 States. JAMA Intern Med. 2021;181(1):131. https://doi.org/10.1001/jamainternmed.2020.3857

2. McCarthy CP, Murphy S, Jones-O'Connor M, et al. Early clinical and sociodemographic experience with patients hospitalized with COVID-19 at a large American healthcare system. EClinicalMedicine. 2020;26:100504. https://doi.org/10.1016/j.eclinm.2020.100504.

3. Morgenstern H. Ecologic Studies in Epidemiology: Concepts, Principles, and Methods. Annu Rev Public Health. 1995;16(1):61-81. https://doi.org/ 10.1146/annurev.pu. 16.050195.000425.

4. Wadhera RK, Wadhera $\mathbf{P}$, Gaba $\mathbf{P}$, et al. Variation in COVID-19 Hospitalizations and Deaths Across New York City Boroughs. JAMA. 2020;323(21):2192-2195. https://doi.org/10.1001/jama.2020.7197.
5. U.S. Census Bureau QuickFacts. Accessed April 3, 2021. https://www. census.gov/quickfacts/fact/table/VT,RI,NH,ME,MA,CT/PSTO45219.

6. Dryden-Peterson S, Velásquez GE, Stopka TJ, Davey S, Lockman S, Ojikutu BO. Disparities in SARS-CoV-2 Testing in Massachusetts During the COVID-19 Pandemic. JAMA Netw Open. 2021;4(2):e2037067. https:// doi.org/10.1001/jamanetworkopen.2020.37067.

7. Massachusetts Health Insurance Survey. Center for Health Information and Analysis. Accessed 3 April 2021. https://www.chiamass.gov/massachusetts-health-insurance-survey/.

Publisher's Note Springer Nature remains neutral with regard to jurisdictional claims in published maps and institutional affiliations. 